\title{
A cruise control for Parkinson's disease
}

\author{
Steven J Schiff ${ }^{*}$, Patrick Gorzelic ${ }^{2}$, Alok Sinha \\ From Twentieth Annual Computational Neuroscience Meeting: CNS*2011 \\ Stockholm, Sweden. 23-28 July 2011
}

As our knowledge of Parkinson's disease increases, we are developing sophisticated computational models of the neuronal networks that go awry in this condition. Such models can form a test bed for the rational design of control strategies to reduce the pathological dynamics. Although deep brain stimulation is becoming increasingly popular for treating Parkinson's disease, all of the present stimulation scenarios involve open-loop stimulation that does not take into account the brain's dynamics through feedback.

Most engineering control systems, such as automobile cruise controls, make use of variants of proportionalintegral-differential (PID) control strategies in response to a measured quantity. We here design an optimized PID controller for Parkinson's disease modulation.

We adapted the sparse-structured model of a small network of synaptically coupled neurons in several basal ganglia areas, originally described by [4], to an efficient structured Matlab implementation. The major outputs from the basal ganglia are inhibitory signals from the globus pallidus interna (GPi) to its localized target areas within thalamus. Correspondingly, a natural view is that parkinsonian basal ganglia activity is transduced into motor symptoms through effects on thalamic dynamics. Specifically, computational [2] and data-based [1] analysis shows that pathological GPi synaptic outputs can compromise thalamic relay of excitatory signals, as can be assessed by calculation of a reliability index or by estimation of GPi output patterns.

We assume an overarching principle for control in Parkinson's disease - we never want to put more than 1 multicontact electrode shaft in the brain. We start with $\mathrm{GPi}$ as a target, since the clinical differences between GPi and STN stimulation effects have not been well

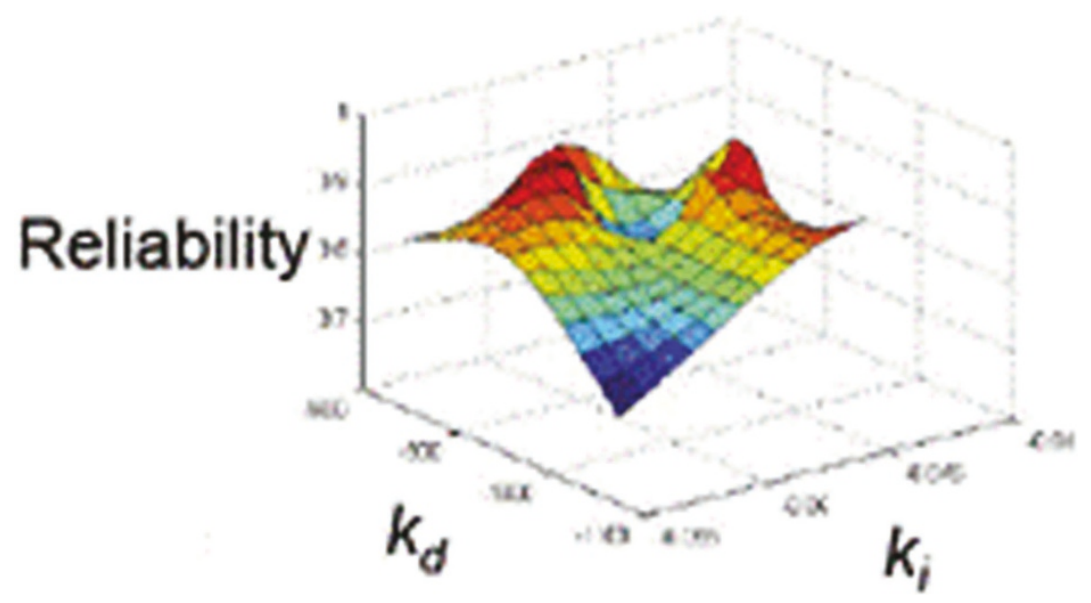

Figure 1 Thalamic reliability as a function of derivative, kd, and integral, ki, terms following exhaustive optimization.

\footnotetext{
* Correspondence: sschiff@psu.edu

${ }^{1}$ Center for Neural Engineering, Penn State University, Pennsylvania, 16802,

USA

Full list of author information is available at the end of the article
}

C Biomed Central

๑ 2011 Schiff et al; licensee BioMed Central Ltd. This is an open access article distributed under the terms of the Creative Commons Attribution License (http://creativecommons.org/licenses/by/2.0), which permits unrestricted use, distribution, and reproduction in any medium, provided the original work is properly cited. 
documented in controlled studies, and the GPi is a larger and easier target into which to insert stereotactic electrodes (see discussion in [3]). We set up 2 empirical control schemes: 1) a reliability control based upon the fraction of the sensorimotor spikes, accurately relayed 1for- 1 by the thalamic cells, and a GPi synaptic control based upon the estimated effective output of the GPi.

We contrast several proportional control schemes based upon reliability: a frequency-proportional case, and a frequency-proportional-biased case. Although the energy expenditure is almost identical for both cases, the reliability is higher with adding a bias term.

We contrast several proportional control schemes using a GPi output controller. Using an amplitude-proportional-derivative control scheme, where the error is equal to the instantaneous calculated GPi synaptic output minus the average GPi output. We flip the sign of the derivative term, from positive to negative, to explore whether amplifying or suppressing the instantaneous response to the differential error is best. Use of a negative differential coefficient yields substantially greater reliability and lower energy expenditure.

Finally, we exhaustively optimize a PID controller using proportional, derivative, and integral terms, as shown in as shown in Figure 1.

We have shown the feasibility of rational PID controller design for Parkinson's disease. Both reliability, and GPi synaptic outputs, can be estimated from reduced model based sensors, and the results of the PID scheme instituted in trials with real feedback controllers. Developing these reduced models for incorporation into future devices is the next step of this research.

\section{Author details}

${ }^{1}$ Center for Neural Engineering, Penn State University, Pennsylvania, 16802, USA. ${ }^{2}$ Department of Mechanical Engineering, Penn State University,

Pennsylvania, 16802, USA.

Published: 18 July 2011

\section{References}

1. Guo Y, Rubin JE, McIntyre CC, Vitek JL, Terman D: Thalamocortical relay fidelity varies across subthalamic nucleus deep brain stimulation protocols in a data-driven computational model. J Neurophysiol 2008, 99(3):1477-92.

2. Rubin JE, Terman D: High frequency stimulation of the subthalamic nucleus eliminates pathological thalamic rhythmicity in a computational model. J Comput Neurosci 2004, 16(3):211-35.

3. Schiff SJ: Towards model-based control of parkinson's disease. Philosophical Transactions of the Royal Society of London Series A 2010.

4. Terman D, Rubin JE, Yew AC, Wilson CJ: Activity patterns in a model for the subthalamopallidal network of the basal ganglia. J Neurosci 2002, 22(7):2963-76.

doi:10.1186/1471-2202-12-S1-P304

Cite this article as: Schiff et al: A cruise control for Parkinson's disease. BMC Neuroscience 2011 12(Suppl 1):P304.

\section{Submit your next manuscript to BioMed Central and take full advantage of:}

- Convenient online submission

- Thorough peer review

- No space constraints or color figure charges

- Immediate publication on acceptance

- Inclusion in PubMed, CAS, Scopus and Google Scholar

- Research which is freely available for redistribution

Submit your manuscript at www.biomedcentral.com/submit
C Biomed Central 